\title{
DOSSIER
}

\section{APORTES Y DISCUSIONES EN ZOOARQUEOLOGÍA DESDE EL MUSEO DE LA PLATA}

\section{CONTRIBUTIONS AND DISCUSSIONS IN ZOOARCHAEOLOGY FROM THE MUSEO DE LA PLATA}

\author{
Laura Marchionni ${ }^{1}$, Emiliano Mange ${ }^{2}$ y Eloísa García Añino 3 \\ ${ }^{1}$ CONICET - División Arqueología, Facultad de Ciencias Naturales y Museo, Universidad \\ Nacional de La Plata. Anexo Museo, Av. 122 y 60 (1900), La Plata. \\ E-mail: lau_marchionni@yahoo.com.ar \\ ${ }^{2}$ División Arqueología, Facultad de Ciencias Naturales y Museo, Universidad Nacional de \\ La Plata. Anexo Museo, Av. 122 y 60 (1900), La Plata. E-mail: emilianomange@gmail.com \\ ${ }^{3}$ División Arqueología, Facultad de Ciencias Naturales y Museo, Universidad Nacional de \\ La Plata. Anexo Museo, Av. 122 y 60 (1900), La Plata. E-mail: eloisagarcia89@yahoo.com.ar
}

La zooarqueología se ha constituido como uno de los pilares de la arqueología del siglo XX (Borrero 2011), y en un sentido amplio, es entendida como la subdisciplina que estudia los restos de animales que encontramos en los sitios arqueológicos. Siguiendo a Lyman (1994), podemos considerar dos objetivos principales del estudio de las arqueofaunas: la reconstrucción de las condiciones paleoecológicas y de los patrones de subsistencia. En ese mismo sentido, Mengoni Goñalons (2007: 14) destaca dos variantes dentro del campo disciplinario: la zooarqueología propiamente dicha y la arqueología biológica. Mientras que la primera, cuyo foco está puesto en la relevancia cultural de los restos óseos, busca conocer las distintas formas de interacción entre los grupos humanos y los animales a través del tiempo, incluyendo desde cambios en las estrategias de subsistencia y movilidad hasta aspectos sociales y simbólicos, la segunda, está más interesada en la comparación de las distribuciones de la fauna en el pasado y en el presente. Ambas perspectivas son complementarias y sinérgicas (Borrero 2011; Mengoni Goñalons 2007), y sus objetivos van más allá del necesario análisis exhaustivo de restos faunísticos hallados en sitios arqueológicos ya que los intereses de la zooarqueología son compartidos por los de otras disciplinas, lo que según Borrero (2011) le da la característica de transdiciplinaria. Debido a ello, la interacción con información de otros materiales y disciplinas (e.g. etnohistoria, etnoarqueología), se vuelve relevante a estos fines. 
Los restos faunísticos registrados en los sitios arqueológicos, son resultado tanto del transporte selectivo y el procesamiento realizado por los humanos, como de otros agentes y procesos (Nash y Petraglia 1987). El interés de la tafonomía radica en entender "los procesos que generan, modifican y destruyen los conjuntos óseos" (O'Connor 2000: 19); de esta manera, la tafonomía se constituye como parte integral de la zooarqueología (Borrero 2011). Así, se vuelve un eje clave para el estudio e interpretación de los contextos arqueofaunísticos ya que sus aportes permiten apuntalar la construcción de ese conocimiento (Borrero 2011; Gutiérrez 2009; Lyman 1994; Marean 1995; Mondini y Muñoz 2014).

Existen numerosos trabajos en los que se detalla la historia de las investigaciones zooarqueológicas en Argentina (e.g. Mengoni Goñalons 2007, 2010) y no es nuestra intención aquí tratar sobre cómo ha sido ese proceso. Sin embargo, nos interesa resaltar la importancia de la Facultad de Ciencias Naturales y Museo de la Universidad Nacional de la Plata en el surgimiento y crecimiento de esta disciplina. Esta casa de estudios se destaca por haber sido pionera en la formación de zooarqueólogos desde fines de la década de 1970 en el país. En este sentido, y tal como refiere Mengoni Goñalons (2007), las investigaciones desarrolladas por los paleontólogos Eduardo P. Tonni y Alberto L. Cione han sido fundamentales para impulsar esta línea de investigación. A partir de entonces el registro óseo empieza adquirir un rol más protagónico en las investigaciones arqueológicas y eso se ve reflejado en que las primeras tesis doctorales que en Argentina estudian de manera exclusiva materiales zooarqueológicos, aunque con distintas perspectivas, son de esta misma facultad (Miotti 1989; Salemme 1987). El impulso que tomó la disciplina en esta Unidad Académica, se debe en gran parte, a que la enseñanza de la Antropología tuvo desde sus comienzos una fuerte tradición de corte naturalista, la cual no se ha perdido incluso con la institucionalización de la carrera de licenciatura a mediados del siglo XX (Ottenheimer 2008). Esto ha promovido una perspectiva ecológica e histórica única de la enseñanza de la antropología en el país ya que es la única facultad donde las tres disciplinas básicas que conforman la esfera zooarquelógica son carreras de grado: antropología, paleontología y zoología. En ese mismo sentido, no es casual que la materia Zooarqueología forme parte desde el año 2000 de las materias optativas y de posgrado que se pueden cursar en esta casa de estudios.

En este dossier se reúnen seis trabajos inéditos que fueron presentados como parte del taller "Aportes y discusiones en Zooarqueología". Este taller, tuvo lugar el 19 de octubre de 2018 en el auditorio del Museo de La Plata, y forma parte de los que viene organizando la División Arqueología de esta institución desde el año 2016, con el interés de dar a conocer las actividades de investigación que se están desarrollando en distintos puntos del país. El objetivo general del taller de zooarqueología fue el de generar un espacio de divulgación, intercambio y discusión, de investigaciones y/o problemas científicos referidos a la práctica zooarqueológica. Los trabajos que aquí se presentan dan cuenta de la gran diversidad de contextos geográficos y cronológicos que, en la actualidad, están 
siendo estudiados desde la perspectiva de la zooarqueología. En este sentido, el presente dossier refleja el estudio de muestras faunísticas provenientes de sitios arqueológicos localizados en distintas regiones del país: Nordeste, Noroeste, Pampa, ciudad de Buenos Aires y Patagonia (2), y el abordaje de distintas problemáticas que guardan relación con los aspectos particulares de los escenarios e investigaciones en las cuales cada uno de ellos se enmarca. La cronología de los conjuntos analizados es asimismo variable, e incluye conjuntos del Holoceno Medio (Bottari y Valiza Davis, Marchionni et al.), del Holoceno tardío (Zarza et al., Day Pilaría), del periodo Inka (Valderrama y Giovannetti), así como de contextos urbanos del siglo XIX (Igareta et al.).

En el trabajo de Mariana Valderrama y Marco Giovannetti, titulado “Animales y ritualidad en el mundo inka. Un caso de estudio en el sitio arqueológico El Shincal de Quimivil (Londres, Catamarca)", se discuten los resultados del análisis de la muestra proveniente de un recinto del sitio El Shincal de Quimivil, capital inkaica ubicada en el valle de Hualfín (Pcia. de Catamarca). Los autores analizan el conjunto poniendo énfasis en las modificaciones óseas y los distintos agentes y procesos responsables de la acumulación. Concluyen que gran parte del conjunto tiene origen antrópico y proponen, de acuerdo con características de la muestra faunística, rasgos arquitectónicos, otros materiales y comparación con sitios inkaicos similares, que los recursos faunísticos fueron utilizados en prácticas de comensalismo ritual en el marco de las festividades realizadas en el sitio. Por otro lado, en el trabajo de Zarza y colaboradores ("Variación temporal en la estructura de los recursos en un sitio del Chaco húmedo argentino"), se presenta una revisión de los materiales faunísticos del sitio El Cachapé Potrero IVB, ubicado en cercanías de un arroyo que forma parte de la cuenca del Plata, en el extremo Este de la provincia de Chaco. Los datos obtenidos a partir del análisis por separado de los dos componentes recientemente identificados en el sitio, son comparados con los presentados por Santini (2009) previo al reconocimiento de las distintas ocupaciones. Se presentan también dos fechados que ubican uno de los componentes en la transición entre el Holoceno tardío inicial y Holoceno tardío final, y el otro en el Holoceno tardío final. Las sociedades de cazadores recolectores que ocuparon el sitio aprovecharon principalmente recursos obtenidos en ambientes fluviales, como peces, aves, coipos y ciervo de los pantanos. Una propuesta interesante de este trabajo es que se exploran las causas de los cambios en la subsistencia a través del tiempo, considerando cambios climáticos y un achicamiento del área de captación de recursos.

Los trabajos de Igareta y colaboradores, y de Day Pilaría, tratan con muestras provenientes del extremo sur de la cuenca del Plata, aunque los contextos de origen son completamente diferentes. En el primero de ellos (Igareta et al.: "Insectos en contextos urbanos: su rol como evidencia en un caso de reuso de objetos del siglo XIX") se presenta el análisis de restos de insectos hallados en el interior de una botella proveniente de una letrina y pozo de basura ubicado en la Ciudad de Buenos Aires y correspondiente al siglo XIX. La presencia de insectos saprófagos (moscas) y sus predadores (coleópteros) es 
utilizada para inferir prácticas de reutilización de los envases de vidrio. De esta manera, el trabajo contrasta con los demás por su objeto de estudio y cronología. Por otra parte, el trabajo de Fernanda Day Pilaría ("Pocos cortes, ¿buenos procesadores? El caso de los conjuntos arqueofaunísticos de los sitos del litoral del río de La Plata"), estudia muestras correspondientes a contextos ubicados en los partidos de Magdalena y Punta Indio, provincia de Buenos Aires. Los conjuntos en cuestión provienen de sitios prehispánicos correspondientes a sociedades "cazadoras, recolectoras, pescadoras y ceramistas". La autora compara contextos de distintos momentos del Holoceno Tardío: en los más antiguos (1800-1500 años AP) predominan las actividades de pesca y la caza de venado y roedores; posteriormente (1000 años AP) la predomina la caza sobre la pesca y luego, ya en ocupaciones postcontacto (300 años AP) no se registra evidencia de pesca y predomina la caza de grandes vertebrados, tanto nativos (ñandú, venado) como introducidos (vacunos). Una de las características tafonómicas constantes en las muestras es la escasez de huellas de corte, y la autora plantea en la discusión, diversas hipótesis para explicar esta situación, entre ellas prácticas de cocción, procesos tafonómicos, y otras.

Por último, los trabajos de Marchionni y colaboradoras ("La fracturación de huesos largos durante el Holoceno Medio en el Macizo del Deseado. Implicancias para el estudio del aprovechamiento de los guanacos") y de Bottari y Valiza Davis ("Los restos óseos del sitio arqueológico La Mesada (meseta Central de Santa Cruz): una aproximación tafonómica") presentan estudios realizados a partir del análisis de contextos del Holoceno medio de la Patagonia meridional.

El trabajo de Marchionni et al. evalúa la variabilidad existente en la fracturación de los huesos largos de Lama guanicoe (guanaco) para el Holoceno medio en el Macizo del Deseado (Santa Cruz, Patagonia argentina). El análisis involucra los conjuntos zooarqueológicos de Piedra Museo y Cueva Maripe, ambos sitios se hallan ubicados en sectores diferentes de la cuenca de los zanjones Rojo y Blanco. El objetivo de las autoras fue alcanzar una mejor comprensión de las estrategias de uso y aprovechamiento de los guanacos por parte de los cazadores-recolectores que habitaron esta región en el pasado y aportar información de grano fino para el estudio de la variabilidad registrada en sitios domésticos o de actividades múltiples. El estudio contempló el análisis y la discusión de las distintas actividades que pudieron involucrar la fracturación intencional de los huesos en el pasado, y los resultados dan cuenta de diferencias entre los conjuntos, mostrando una mayor la variedad de actividades vinculadas a la fracturación de huesos en Cueva Maripe que en Piedra Museo.

Finalmente, el trabajo de Camila Bottari y Catalina Valiza Davis presenta los resultados de los primeros estudios tafonómicos del sitio arqueológico La Mesada, ubicado en la localidad La María, también en la Meseta Central de Santa Cruz. Desde una perspectiva tafonómica, las autoras evaluaron la composición, el origen y los procesos que modificaron el conjunto faunístico del componente correspondiente al Holoceno Medio, 
donde Lama guanicoe es la especie más representada. Los resultados indican que el principal agente acumulador de los restos óseos ha sido el antrópico, no obstante, el reconocimiento macroscópico de diferentes patrones de modificación en las superficies óseas les permite a las autoras reconocer y discutir la importancia del agua como agente tafonómico en la formación del conjunto. Este agente habría producido cambios en las superficies óseas, y además habría contribuido a la destrucción de especímenes.

\section{Bibliografía citada}

Borrero, L. A.

2011 La función transdiciplinaria de la arqueozoología en el siglo XXI: restos animales y más allá. Antípoda 13: 267-274.

Gutiérrez, M. A.

2009 Tafonomía: ¿Tiranía o multivocalidad? En Perspectivas actuales en Arqueología Argentina, R. Barberena, K. Borrazzo y L. A. Borrero (eds.), pp. 57-87. CONICETIMHICIHU, Buenos Aires.

Lyman, R. L.

1994 Vertebrate Taphonomy. Cambridge University Press, Cambridge.

Marean, C. W.

1995 Of taphonomy and zooarchaeology. Evolutionary Anthropology 4 (2): 64-72.

Mengoni Goñalons, G. L.

2007 Archaeofaunal studies in Argentina: a historical overview. En Taphonomy and zooarchaeology in Argentina, M. Gutiérrez; L. Miotti; G. Barrientos; G. L. Mengoni Goñalons y M. Salemme (eds.), pp. 13-34. BAR International Series n ${ }^{\circ} 1601$, Manchester.

2010 Advances in animal bone archaeology in Argentina: general trends and some prospects for the future. En Arqueozoología latinoamericana: orígenes y desarrollo, G. L. Mengoni Goñalons, J. Arroyo-Cabrales, O. J. Polaco, y F. J. Aguilar (eds.), pp. 15-24. Instituto Nacional de Antropología e Historia para la Ciencias y la Tecnología, Consejo Nacional para la Ciencia y la Tecnología e International Council for Archaeozoology, México.

Miotti, L.

1989 Zooarqueología de la Meseta Central y costa de la provincia de Santa Cruz: un enfoque de las estrategias adaptativas aborígenes y los paleoambientes. Tesis doctoral inédita. Facultad de Ciencias Naturales y Museo, Universidad Nacional de La Plata. 
Mondini, M. y S. Muñoz.

2014 La Tafonomía en la zooarqueología argentina de los últimos veinte años: su representación en las publicaciones periódicas y reuniones académicas nacionales. Revista Chilena de Arqueología 29 (1): 95-101.

Nash, D. T. y M. D. Petraglia.

1987 Natural formation processes and the archaeological record: present problems and future requisites. En Natural formation process and the archaeological record, D. T. Nash y M. D. Petraglia (eds), pp. 186-204. BAR Internacional Series nº 352, Manchester.

O'Connor, T.

2000 The Archaeology of Animal Bones. Sutton Publishing, Stroud.

Ottenheimer, A. C.

2008 La creación de la licenciatura en Antropología en La Plata: un aporte a la historia de la enseñanza de la disciplina. Trabajo presentado en el IX Congreso Argentino de Antropología Social, Posadas, Argentina.

Salemme, M.

1987 Paleoetnozoología del sector bonaerense de la Región Pampeana con especial atención a los mamíferos. Tesis Doctoral inédita. Facultad de Ciencias Naturales y Museo, Universidad Nacional de La Plata. 